\title{
Nutritional composition of takeaway meals served by independent small outlets
}

\author{
A. Jaworowska, T. Blackham and L. Stevenson \\ Liverpool John Moores University, I.M. Marsh Campus, Liverpool, L17 6BD, UK
}

Eating out of the home is growing in popularity and about $22 \%$ of Britons have been found to purchase foods from takeaway outlets at least once a week and $58 \%$ a few times a month ${ }^{(1)}$. Foods prepared outside the home are generally considered to be high in energy, saturated and trans fatty acids, total fat and salt ${ }^{(2)}$. While previous studies have investigated the nutritional quality of food provided by fast food chains, there is still a lack of data regarding the nutrient composition of meals purchased from independent takeaway outlets.

Takeaway meal samples were collected from small independent takeaway establishments. Components such as energy, total fat and salt were determined. The 463 samples of twenty three different takeaway meals were classified into five groups (Chinese, Indian, English, Pizzas, Kebabs). The variability in the mean nutrient content across and within meal groups, and in the same type of meal but purchased from different establishments was assessed using Kruskal-Wallis Anova, statistical significance $P<0.05$. The results are presented as mean (minimum-maximum).

Results showed that takeaway meals contain high levels of fat and salt and are energy dense, regardless of the type of cuisine. Significant variation in the mean nutrient content per $100 \mathrm{~g}$ across and within product categories was also observed. Pizzas were characterised by the highest mean level of salt $(1.41 / 100 \mathrm{~g})$, total fat $(12.0 \mathrm{~g} / 100 \mathrm{~g})$ and energy content $(1179.888 \mathrm{~kJ} / 100 \mathrm{~g}(282 \mathrm{kcal} / 100 \mathrm{~g}))$ when compared with other meal categories.

Table 1. Nutrient content of takeaway meal categories

\begin{tabular}{lccrr}
\hline Meal category & $\begin{array}{c}\text { Weight of portiong } \\
(\min -\max )\end{array}$ & $\begin{array}{c}\text { Energy kJ*/100g } \\
(\min -\max )\end{array}$ & $\begin{array}{c}\text { Fat g/100g } \\
(\min -\max )\end{array}$ & \multicolumn{1}{c}{$\begin{array}{c}\text { Salt g/100g } \\
(\min -\max )\end{array}$} \\
\hline Chinese $N$ 124 & $852(456-1281)$ & $635.96(317.98-999.97)$ & $5.4(0.9-12.3)$ & $0.95(0.15-3.05)$ \\
Indian $N$ 95 & $804(600-1061)$ & $719.65(464.42-1125.49)$ & $8.4(1.7-16.1)$ & $0.62(0.30-1.22)$ \\
English $N$ 95 & $747(467-1076)$ & $941.4(707.09-1230.09)$ & $11.3(6.3-17.2)$ & $0.46(0.08-1.30)$ \\
Pizzas $N$ 54 & $698(352-1280)$ & $1179.88(1029.26-1343.06)$ & $12.0(8.0-18.0)$ & $1.41(0.74-2.41)$ \\
Kebabs $N$ 75 & $581(237-1208)$ & $849.35(472.79-1510.42)$ & $9.0(1.0-23.6)$ & $1.13(0.13-2.97)$ \\
$P$ & $<0.001$ & $<0.001$ & $<0.001$ & $<0.001$ \\
\hline *1 kcal $=4.184 \mathrm{~kJ}$. & & &
\end{tabular}

There were also substantial differences in the nutrient composition of similar meals purchased from different establishments. For example, Chicken in Blackbean sauce contained between 430.952 and $753.12 \mathrm{~kJ}$ of energy per $100 \mathrm{~g}, 1.6-8.1 \mathrm{~g}$ fat per $100 \mathrm{~g}$ and 0.14 $1.2 \mathrm{~g}$ of salt per $100 \mathrm{~g}$ depending on the outlet. It should be pointed out that the variability in the nutrient composition was greater for comparisons per portion rather than per $100 \mathrm{~g}$ due to inconsistent portion sizes between outlets.

While the variability in nutritional composition of the different meal categories was expected and is natural, the wide variation of nutrient content of similar meals may provide an opportunity for recipe reformulation to improve the nutritional quality of takeaway foods.

1. Food Standard Agency (2007) Consumer attitudes to food standards. Wave 7.

2. Stender S, Dyerberg J \& Astrup A (2007) Int J Obes 31, 887-890. 